\title{
DIFFERENTIAL EFFECTS OF CAMP AND cGMP ON IN VITRO EPIDERMAL CELL GROWTH
}

\author{
CYNTHIA L. MARCELO \\ University of Michigan Medical School, Dermatology Research Labs, \\ Kresge I research bldg, R-6558, Ann Arbor, MI 48109, USA
}

\begin{abstract}
SUMMARY
Primary keratinocyte cultures free of dermal fibroblasts were used to investigate the effect of varying cyclic AMP (cAMP) concentrations on epidermal cell function. Addition of $10^{-3}, 10^{-4}$ or $10^{-5} \mathrm{M}$ dibutyryl cAMP to plated cells (day 1) results by day 5 in a dose dependent increase of $\left[{ }^{3} \mathrm{H}\right] \mathrm{TdR}$ incorporation into DNA as determined by increases in both the labeling index and incorporation of ${ }^{3} \mathrm{H}$ label into an isolated DNA fraction. 8-Bromo cAMP, another cAMP analogue, likewise induced keratinocyte proliferation. The proliferative response was dose and time dependent, and 5- to 6-fold increases in ${ }^{3} \mathrm{H}$ label incorporated into DNA were seen at day 6, 8 and up until day 15 of culture. Moreover, elevation of cellular cAMP by addition of cholera toxin, an irreversible stimulator of adenylate cyclase, also demonstrated a time dependent stimulation of $\left[{ }^{3} \mathrm{H}\right] \mathrm{TdR}$ uptake into DNA and increased the labeling index. Specific histochemical staining for keratinaceous protein (Kreyberg technique) demonstrated that elevated cAMP levels also enhance the production of specialized (differentiated) epidermal cells. Determination of the level of cAMP and cyclic GMP (cGMP) by RIA of partially purified fractions of the cultures revealed that addition of 8-bromo cAMP or cholera toxin to the cultures increased the levels of cAMP but not of cGMP. Addition of 8-bromo cGMP to the keratinocytes on day 1 at concentrations of $10^{-6}, 10^{-7}$ or $10^{-8} \mathrm{M}$ had no effect on culture proliferation on days 4,6 and 8 , although qualitative changes in the electron microscopic pattern of the culture stratification and specialization were observed. The results indicate (1) both large and moderate increases in cellular cAMP levels induce keratinocyte culture proliferation and specialization in the absence of fibroblasts or dermal influences, (2) the quantitative enhancement of keratinocyte growth and specialization occurs without apparent participation of cGMP, (3) cGMP may be a qualitative effector of epidermal cell differentiation.
\end{abstract}

Changes in cyclic nucleotides can influence the growth and differentiation (specialization) of a variety of cell types. The direction of proliferation-differentiation events associated with changes in cyclic AMP (cAMP) and cyclic GMP (cGMP) has been the subject of numerous investigations (see $\operatorname{ref}[1,2]$ for review). The diversity of methodology and model systems [3-6], and unique individual cell type response to cyclic nucleotide fluctuations [7-11] have probably resulted in a large portion of the reported discrepancies in the literature. Because of this, no unified hypothesis as to the role of cAMP and cGMP in eukaryotic cells can be formulated at this time. As a result, the cyclic nucleotide system of each individual cell system must be investigated, focusing on a cell's own unique cAMP and cGMP regulatory mechanisms.

The cyclic nucleotide modulatory system has been reported to be involved in several proliferation-differentiation disorders of human epidermis [12-15]. The data resulting from cyclic nucleotide [16-18], and related enzyme(s) [16-19] and receptor [20] assays of epidermal biopsy material do suggest abnormalities in this regulatory system, although these systems are not technically amenable to delineate the functional aspects 
of cyclic nucleotide modulation of the epidermis. Therefore, an in vitro epidermal cell culture system was used to define possible cyclic nucleotide regulatory mechanisms in epidermal function. The neonatal mouse keratinocyte cultures used in these experiments are free of co-cultured dermal fibroblasts and require minimal medium additives to demonstrate orderly and reproducible proliferative patterns, stratification to 6-8 cell layers and keratinocyte specialization for greater than 4 weeks [21].

The present study provides evidence that both large and moderate increases in keratinocyte cAMP levels induce proliferation and culture stratification and specialization. Added 8-bromo cGMP was found to have no apparent effect on cell proliferation and was observed to cause marked changes in keratinocytes specialization as observed by electron microscopy.

\section{MATERIALS AND METHODS}

\section{Reagents}

Medium 199 (modified, Earle's salts, glutamine), fetal calf serum, Penicillin and Streptomycin (P \& S), Lux plastic coverslips and all phosphate buffered saline solutions (PBS) were obtained from Flow Laboratories, Rockville, MD. Dibutyryl cAMP (db-cAMP) ( $\mathrm{N}^{6}, \mathrm{O}^{2}$-dibutyryl adenosinc $3^{\prime}: 5^{\prime}$-cyclic monophosphate; $\mathrm{Bt}_{2} \mathrm{cAMP}$ ), 8-bromo cAMP (8-bromoadenosine $3^{\prime}: 5^{\prime}$-cyclic monophosphate; 8-brcAMP), 8-bromo cGMP (8-bromoguanosine 3':5'-cyclic monophosphate; 8-BrcGMP), 8-bromo 5'AMP, Ficoll 400 and trypsin type III were obtained from Sigma, St Louis, Mo. Cholera Toxin (lot no. 0172) was a gift from C. E. Miller, Cholera program officer, NIAD, Bethesda, Md. Methylisobutylxanthine (MIX) was supplied by Searle and Co., Chicago, Ill. Saffron (Chroma-Gesellschaft) is distributed by Roboz Surgical Inst. Co., Washington, D.C., and other histological stains were from Matheson, Coleman and Bell, East Rutherford, N.J. AG 50W-X8 (100-200 mesh, $\mathrm{H}^{+}$ form) and $\mathrm{AG} 1-\mathrm{X} 2$ (200-400 mesh, $\mathrm{Cl}^{-}$form) were purchased from Bio-Rad Laboratories, Richmond, Ca ${ }^{125}$ I-labeled ScAMP-TME and ScGMP-TME ligand for radioimmunoassay (RIA) were supplied by Collaborative Res, Boston, Mass. The anti-cAMP (titer: 1-5000) and anti-cGMP (titer, 1-20000) sera were produced in rabbits and show high specificity. Uranyl acetate was obtained from Mallinckrodt, St Louis, Mo, and Epon 812 from Ladd, Res., Burlington, Vt. $\left[{ }^{3} \mathrm{H}\right]-$
TdR (60 Ci/mMol) was purchased from New England Nuclear, Boston, Mass. Corning Plastic products (Corning, N.Y.) were used in all phases of cell isolation and growth.

\section{Epidermal cell cultures}

The primary keratinocyte cultures were prepared as previously described [21]. Full thickness skin from $40-60$ neonatal BALB/c mice is trypsinized $(0.25 \%)$ for $1 \mathrm{~h}$ at $37^{\circ} \mathrm{C}$. The epidermal cells that are isolated after manual separation of the dermis from the epidermis are further purified from any dermal fibroblasts and debris by use of a discontinuous Ficoll gradient. $2 \times 10^{5}$ trypan-blue excluding cells are plated $/ \mathrm{cm}^{2}$ in medium 199 plus $13 \%$ fetal calf serum (FCS) and containing $50 \mathrm{IU} / \mathrm{ml}$ of penicillin and $50 \mathrm{ug} / \mathrm{ml}$ of streptomycin. The cells are grown in $5 \% \mathrm{CO}_{2}$ in air gassing at $33^{\circ} \mathrm{C}$. The medium is changed every second day. The dissociation procedure were designed to eliminate any co-cultured fibroblasts. The absence of dermal fibroblasts was shown by use of the leucine aminopeptidase histochemical technique which can detect one fibroblast $/ 2 \times 10^{4}$ keratinocytes [21].

The cAMP and CGMP analogues, and cholera toxin were added to the cultures on day 1 unless otherwise specified and with each medium change.

\section{Methods of assay}

To quantitate the incorporation of $\left[{ }^{3} \mathrm{H}\right] \mathrm{TdR}$ into keratinocyte culture DNA, the monolayers were pulsed for $6 \mathrm{~h}$ with $1 \mu \mathrm{Ci} / \mathrm{ml}$ of $60 \mathrm{Ci} / \mathrm{mMol}$ of $\left[{ }^{3} \mathrm{H}\right] \mathrm{TdR}$. After rinsing the monolayers twice with cold Dulbecco's PBS, the cells were scraped with $4 \mathrm{ml}$ of cold $6 \%$ trichloroacetic acid (TCA). The precipitate was washed twice with $2 \mathrm{ml}$ of $6 \%$ TCA. One $\mathrm{ml}$ of the $6 \%$ TCA fraction was counted to determine the $\left[{ }^{3} \mathrm{H}\right] \mathrm{TdR}$ acid-soluble fraction. Unless specified, the cpm of ${ }^{3} \mathrm{H}$ label in the acid-soluble fraction of the experimental cells was that of the control. The $6 \%$ TCA pellet was hydrolyzed with $3 \%$ PCA and aliquots of the supernatant were counted to quantitate the ${ }^{3} \mathrm{H}$ label into DNA and assayed colorimetrically for DNA [22].

The RIA for cAMP and cGMP were done as reported [17]. The partially purified cAMP and cGMP fractions were acetylated as reported by Harper \& Brooker [23]. Use of 3 different dilutions, cyclic nucleotide phosphodiesterase digestion of samples (prior to acetylation) and internal standards verified the accuracy of the assays. The ${ }^{125}$ I-labeled ligand was obtained from Collaborative Res., and the anti-cAMP and cGMP sera was produced in rabbits as described by Steiner et al. [24].

All fractions and assays were counted using dioxanenaphthalene based or toluene-ethoxyethanol based (RIA) scintillation fluid in a Packard Tri-carb scintillation counter ( $60 \%$ efficiency for tritium).

\section{Autoradiography}

Cells were grown on Lux coverslips and labeled for $18-20 \mathrm{~h}$ with $1 \mu \mathrm{Ci} / \mathrm{ml}$ of $\left[{ }^{3} \mathrm{H}\right] \mathrm{TdR}$. After fixation, the coverslips were processed for autoradiography as described [21]. 
Cholera toxin study in $13 \%$ and

\section{$1 \% \mathrm{FCS}$}

The medium was removed from day 1 cells and medium 199 plus $1 \%$ FCS containing $50 \mu \mathrm{M}$ MIX was added to one set of experimental T-25 flasks. Medium 199 plus $13 \%$ FCS plus $50 \mu \mathrm{M}$ MIX was added to the other set of experimental flasks. Either $13 \%$ or $1 \%$ Medium 199 was added to the control flasks (no MIX). The cholera toxin was added to each of the $13 \%$ and $1 \%$ FCS experimentals. Enough FCS was added to the control and experimental flasks in the $1 \%$ FCS medium to yield a final concentration of $13 \%$ after $3 \mathrm{~h}$. The cholera toxin and MIX were readded with each medium change.

\section{Histochemical stains and electron microscopy}

The Kreyberg stain was done as reported [21]. After fixation, the cultures and cryostated sections of neonatal mouse skin were stained with Mayer's hematoxylin, $1 \%$ aqueous erythrosin and a saffron solution. The basal cell layer of the whole skin shows only nuclear blue-grey stain while the spinous, granular and stratum corneum layers (non-proliferative and specializing cells) stain a vivid red color (erythrosin). As the cultures stratify and specialize in vitro, the redstaining material developes [21].

For electron microscopy, the cultures were treated as previously reported [21]. Sections were examined with Philips 300 electron microscope at $60 \mathrm{kV}$.

\section{RESULTS}

Effect of db-cAMP and 8-bromo

\section{cAMP on keratinocyte}

\section{proliferation}

Dibutyryl cAMP was added to the cultures on day 1 to give a final concentration of $10^{-3}, 10^{-4}$ or $10^{-5} \mathrm{M}$. Table 1 presents the data showing the effect of this CAMP analogue on the incorporation of $\left[{ }^{3} \mathrm{H}\right] \mathrm{TdR}$ into DNA as determined by quantitation of ${ }^{3} \mathrm{H}$ label into cellular DNA and autoradiography. As shown, db-cAMP stimulated keratinocyte proliferation as assayed by cpm of ${ }^{3} \mathrm{H} / \mu \mathrm{g}$ DNA in a dose dependent manner: $10^{-3} \mathrm{M}$ db-cAMP induced a 3.7 fold and $10^{-4} \mathrm{M}$ db-cAMP produced a 2.0 fold stimulation while $10^{-5} \mathrm{M}$ concentration of the analogue had minimal effect at this time point $(D=5)$. Autoradiography also indicated that the dibutyryl analogue stimulated keratinocyte proliferation. However,
Table 1. Effect of db-cAMP on keratinocyte proliferation

\begin{tabular}{|c|c|c|}
\hline $\begin{array}{l}\text { Conc. } \\
\text { added } D=1 \\
\text { db-cAMP }\end{array}$ & $\begin{array}{l}\text { Incorporation }{ }^{a} \\
{ }^{3} \mathrm{H} \text { into DNA } \\
\mathrm{cpm} / \mu \mathrm{g} \text { DNA }\end{array}$ & $\begin{array}{l}\text { Autoradiography } \\
\text { labeled cells/500 }\end{array}$ \\
\hline $\begin{array}{l}\text { None } \\
10^{-3} \mathrm{M} \\
10^{-1} \mathrm{M} \\
10^{-5} \mathrm{M}\end{array}$ & $\begin{array}{lr}1 & 131 \pm 84 \\
4 & 149 \pm 120 \\
2 & 272 \pm 149 \\
1 & 585+64\end{array}$ & $\begin{array}{l}42.5 \pm 2 \\
107.6 \pm 19 P=0.01 \\
131.0 \pm 27 P=0.004 \\
53.0 \pm 11 \text { N.S. }\end{array}$ \\
\hline \multicolumn{3}{|l|}{ Na Butyrate } \\
\hline $\begin{array}{l}\text { None } \\
10^{-3} \mathrm{M}\end{array}$ & $\begin{array}{l}288 \pm 9 \\
204 \pm 20\end{array}$ & $\begin{array}{l}\text { Not done } \\
\text { Not done }\end{array}$ \\
\hline
\end{tabular}

a Six hour terminal labeling on day $5,5 \mu \mathrm{Ci} /$ flask $\left[{ }^{3} \mathrm{H}\right]$ TdR, $50 \mathrm{Ci} / \mathrm{mMol}$ spec. act. DNA extracted with $3 \%$ PCA after $6 \%$ TCA precipitation. Mean \pm S.E.M. of quadruplicate flasks.

${ }^{b}$ Twenty hour terminal labeling with $5 \mu \mathrm{Ci} /$ flask $\left[{ }^{3} \mathrm{H}\right]$. TdR, day 4 to 5 . Mean \pm S.E.M. of triplicate slides from duplicate T-25 flasks. Student's $t$-test, twosided.

this technique cannot be used to quantitate a dose response since the $4-5$ cell layers that develop by this time absorb the radiation emitted by the ${ }^{3} \mathrm{H}$ label in the DNA before it can interact with the emulsion. $10^{-3} \mathrm{M}$ Na butyrate did not effect keratinocyte proliferation (table 1). Fig. 1 shows the results of a series of overlapping (days) time and dose response experiments using the 8-bromo cAMP analogue. As presented, $10^{-3} \mathrm{M}$ 8-bromo cAMP had no effect on ${ }^{3} \mathrm{H}$ incorporation into cellular DNA 3 and $6 \mathrm{~h}$ after addition. By day 2 , which is $24 \mathrm{~h}$ after the 8-bromo analogue was added, $10^{-3}$ and $10^{-4} \mathrm{M} 8$-bromo cAMP increased keratinocyte proliferation while the $10^{-5} \mathrm{M}$ concentration was not effective until day 6,5 days after exposure to the CAMP analogue. The stimulatory effect of 8-bromo cAMP at these concentrations has been routinely observed (data not presented) until day 15 of culture (the last time point studicd). $10^{-2} \mathrm{M}$ 8-bromo cAMP inhibited keratinocyte proliferation, in concert with monolayer destruction. 


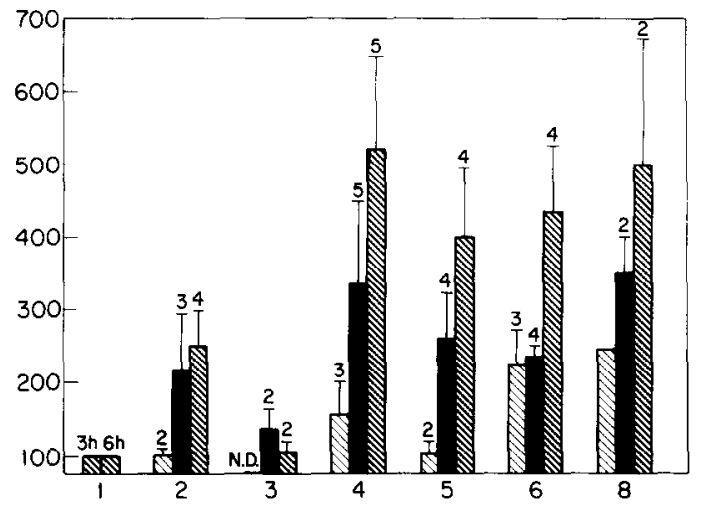

Fig. I. Abscissa: time in culture (days); ordinate: \% control $=\mathrm{cpm} / \mu \mathrm{g} \quad$ DNA/experimental $/ \mathrm{cpm} / \mu \mathrm{g} \quad$ DNA control. $\mathbb{\$}, 10^{-3} \mathrm{M} ; \square, 10^{-4} \mathrm{M} ; \mathbb{\$}, 10^{-5} \mathrm{M}$ 8-Bromo cAMP.

Effect of 8-bromo cAMP on keratinocyte proliferation. Control value, $100 \%$. Bar, mean \pm S.E.M. of separate experiments; the number over each bar designates the $n$ number of experiments, each consisting of triplicate T-25 flasks. Percent control representation of the data is used to facilitate the presentation and statistical analysis of the data since the graph presents the results from 5-6 different cell preparations.

\section{Effect of cholera toxin}

Since 5'AMP and adenosine elevate the levels of cAMP in mouse [25], in human [26] and pig [27] epidermis and in the neonatal mouse cultures (Duell, unpublished results), this nucleotide and nucleoside and their analogues could not be used to test the specificity of the cAMP analogue effects. Cholera toxin is an irreversible stimulator of adenylate cyclase, the enzyme that catalyzes the formation of cAMP from ATP [28, 29]; therefore, it was used to elevate the intracellular levels of keratinocyte cAMP. Fifty $\mu \mathrm{M}$ MIX (1-methyl-3-isobutylxanthine) was also added to inhibit cyclic nucleotide phosphodiesterase activity and thereby maintain the elevated cellular cAMP levels [30].

Since Guerrant et al. [29] reported that $\mathrm{CHO}$ cell response to cholera toxin was maximal in $1 \%$ FCS concentrations, the magnitude of cholera toxin induced cAMP (and cGMP) changes and effect on keratinocyte proliferation when added in the presence of either $1 \%$ or $3 \%$ FCS (first $3 \mathrm{~h}$ ) was ascertained. As presented in table 2, $1 \mu \mathrm{g} / \mathrm{ml}$ cholera toxin in $50 \mu \mathrm{M}$ MIX increased cAMP levels approx. 7- to 8-fold $3 \mathrm{~h}$ to $72 \mathrm{~h}$ after addition; this plateauing effect is similar to that reported by Guerrant et al. in a number of cell lines [29]. The percent of FCS in the medium did not significantly alter the magnitude of the observed change in cAMP or the increase in keratinocyte proliferation that was observed after 48 and $72 \mathrm{~h}$ (approx. 2-fold, table 2). No changes in cGMP were observed. All fur-

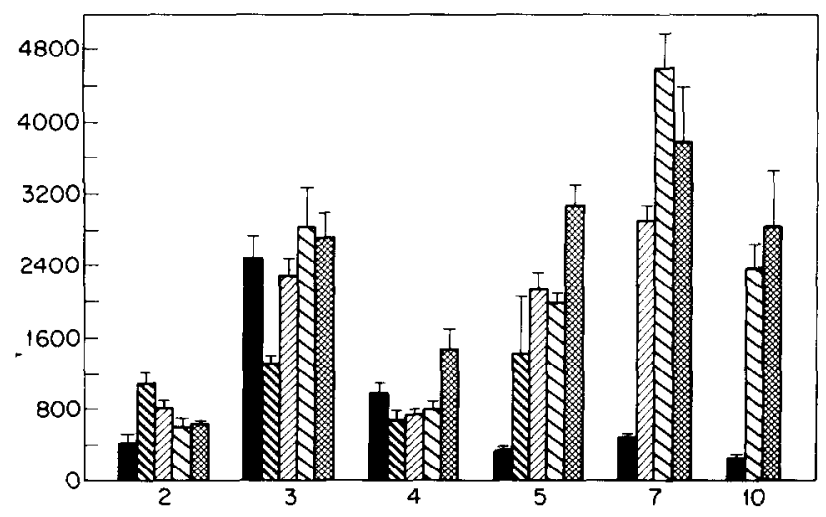

Exp Cell Res 120(1979)
Fig. 2. Abscissa: time in culture (days); ordinate: $\mathrm{cpm} / \mu \mathrm{g} / \mathrm{DNA}$. Control; $\mathbb{\$}, 50$ $\mathrm{pg} / \mathrm{ml} ; 0.5 \mathrm{ng} / \mathrm{ml} ; 50 \mathrm{ng} / \mathrm{ml} ;, 1.0 \mu \mathrm{g} /$ $\mathrm{ml}$ cholera toxin.

Effect of cholera toxin on keratinocyte proliferation. Bars, mean \pm S.E.M. of triplicate flasks, all part of one experimental series. All experimental contained $50 \mu \mathrm{M}$ MIX. 
Table 2. Changes in keratinocyte cyclic nucleotide content effected by cholera toxin and 8-bromo cAMP

\begin{tabular}{|c|c|c|c|c|c|c|c|}
\hline \multirow[b]{2}{*}{ Addition } & \multirow[b]{2}{*}{$\begin{array}{l}\text { Time } \\
\text { (hours) }\end{array}$} & \multicolumn{3}{|l|}{$13 \% \mathrm{FCS}$} & \multicolumn{3}{|l|}{$1 \% \mathrm{FCS}$} \\
\hline & & $\mathrm{cpm}^{u . g}$ & Pmols c AMP & Fmols cGMP & $\mathrm{cpm}^{y}$ & Pmols cAMP ${ }^{g}$ & $\begin{array}{l}\text { Fmols }^{g} \\
\text { cGMP }^{2}\end{array}$ \\
\hline Control & 3 & - & $0.299 \pm 0.038$ & $26.5 \pm 0.5$ & - & $0.560^{d}$ & $16.0^{d}$ \\
\hline $1 \mu \mathrm{g} \mathrm{ct}$ & 3 & - & $2.17 \pm 0.39$ & $22.0 \pm 4.0$ & - & $4.83 \pm 0.88$ & $21.0 \pm 3.0$ \\
\hline Contrul & 48 & $5202 \pm 856$ & $0.40 \pm 0.12$ & $17.5 \pm 12.0$ & $3682 \pm 222$ & $0.39^{d}$ & $37.0 \pm 1.0$ \\
\hline $1 \mu \mathrm{g} \mathrm{ct}$ & 48 & $8315 \pm 982$ & $3.29 \pm 0.044$ & $19.7 \pm 4.0$ & $6791 \pm 808$ & $3.36 \pm 0.90$ & $22.0 \pm 5.0$ \\
\hline Control & 72 & $669 \pm 33$ & $0.296 \pm 0.09$ & $13.0 \pm 1.0$ & $666 \pm 52$ & $0.532 \pm 0.116$ & $12.0 \pm 1.0$ \\
\hline $1 \mu \mathrm{g} \mathrm{ct}$ & 72 & $1303 \pm 54$ & $2.56 \pm 0.13$ & $8.0 \pm 5.0$ & $1228 \pm 157$ & $1.66 \pm 0.090$ & $7.0 \pm 2.0$ \\
\hline Control $^{f}$ & 96 & $530 \pm 57$ & $0.323 \pm 0.056$ & $10.0 \pm 2.0$ & & & \\
\hline $50 \mathrm{ng} \mathrm{ct}$ & 96 & $560 \pm 26$ & $1.117 \pm 0.240$ & $7.0 \pm 1.0$ & & & \\
\hline \multicolumn{8}{|l|}{ 8-BrCAMP } \\
\hline $\mathrm{I} \mathrm{mM}$ & 96 & $1377 \pm 4$ & $21.50 \pm 3.20$ & $10.0 \pm 2.0$ & & & \\
\hline
\end{tabular}

" $6 \mathrm{~h}$ terminal labeling with $1 \mu \mathrm{Ci} / \mathrm{ml}\left[{ }^{3} \mathrm{H}\right] \mathrm{TdR}, 60 \mathrm{Ci} / \mathrm{mMol}$; Mean \pm S.E.M. of triplicate Petri dishes

"Mean \pm S.E.M. of duplicate or triplicate flasks.

r Mean \pm S.E.M. of duplicate or triplicate flasks.

d Mean of quadruplicate RIA determinations of one sample.

" ct, cholera toxin $+50 \mu \mathrm{m}$ MIX.

$\checkmark$ Separate experimental series from above.

After $3 \mathrm{~h}$ exposure to the $\mathrm{CT}$. the cells in $1 \% \mathrm{FCS}$ were restored to $13 \% \mathrm{FCS}$ since this concentration is required for cell growth.

"Each of these measures is calculated per $\mu \mathrm{g}$ DNA.

ther cholera toxin experiments were therefore conducted using $13 \%$ FCS.

Another concentration of cholera toxin, $50 \mathrm{ng} / \mathrm{ml}$, was shown to increase cAMP levels approx. 3.5-fold after exposure of the cells to the toxin for 4 days. No changes in cGMP were observed (table 2). Also presented in table 2 is the result of the cAMP and cGMP RIA of keratinocyte cultures treated with $1 \mathrm{mM}$ 8-bromo cAMP. The $6 \%$ TCA supernatant containing the cyclic nucleotides, and other nucleotides and nucleosides was ether extracted, was precipitated with $\mathrm{ZnAc}-\mathrm{Na}_{2} \mathrm{CO}_{3}$ and subjected to Dowex $50 \times 8$ and Dowex $1 \times 2$ chromatography [17], which separates cAMP from cGMP and both from the 8bromo cAMP analogue. One $\mathrm{mM}$ 8-bromo cAMP was found to increase the cAMP levels (from a control value of $0.32 \pm 0.056$ to $21.50 \pm 3.2 \mathrm{pmol} / \mu \mathrm{g}$ DNA, table 2), a $66-$ fold increase. There was no change in the levels of cGMP.

The results of a time and dose study using four cholera toxin concentrations in the

Table 3. Effect of 8-bromo cGMP on keratinocyte proliferation (cpm/ $/ \mathrm{g} D N A)$

\begin{tabular}{lccc}
\hline \multicolumn{4}{c}{ Days in culture } \\
\cline { 2 - 4 } & 4 & 6 & 8 \\
\hline 8-Bromo cGMP & & \\
None & $147 \pm 27$ & $357 \pm 61$ & $205 \pm 11$ \\
$10^{-6} \mathrm{M}$ & $165 \pm 4$ & $428 \pm 36$ & $296 \pm 40$ \\
$10^{-7} \mathrm{M}$ & $150 \pm 32$ & $216 \pm 44$ & $185 \pm 24$ \\
$10^{-8} \mathrm{M}$ & $92 \pm 13$ & $217 \pm 50$ & $234 \pm 21$ \\
8 -Bromo cAMP & & & \\
None & $758 \pm 103$ & $281 \pm 24$ & $226 \pm 27$ \\
$10^{-3} \mathrm{M}$ & $3361 \pm 57$ & $753 \pm 115$ & $1115 \pm 50$ \\
$10^{-4} \mathrm{M}$ & $1599 \pm 100$ & $687 \pm 10$ & $1042 \pm 29$ \\
$10^{-5} \mathrm{M}$ & $868 \pm 16$ & $335 \pm 57$ & $548 \pm 13$ \\
\hline
\end{tabular}

Mean \pm S.E.M. of quadruplicate $60 \mathrm{~mm}$ Petri dishes. Drugs added $\mathrm{D}=1$. 


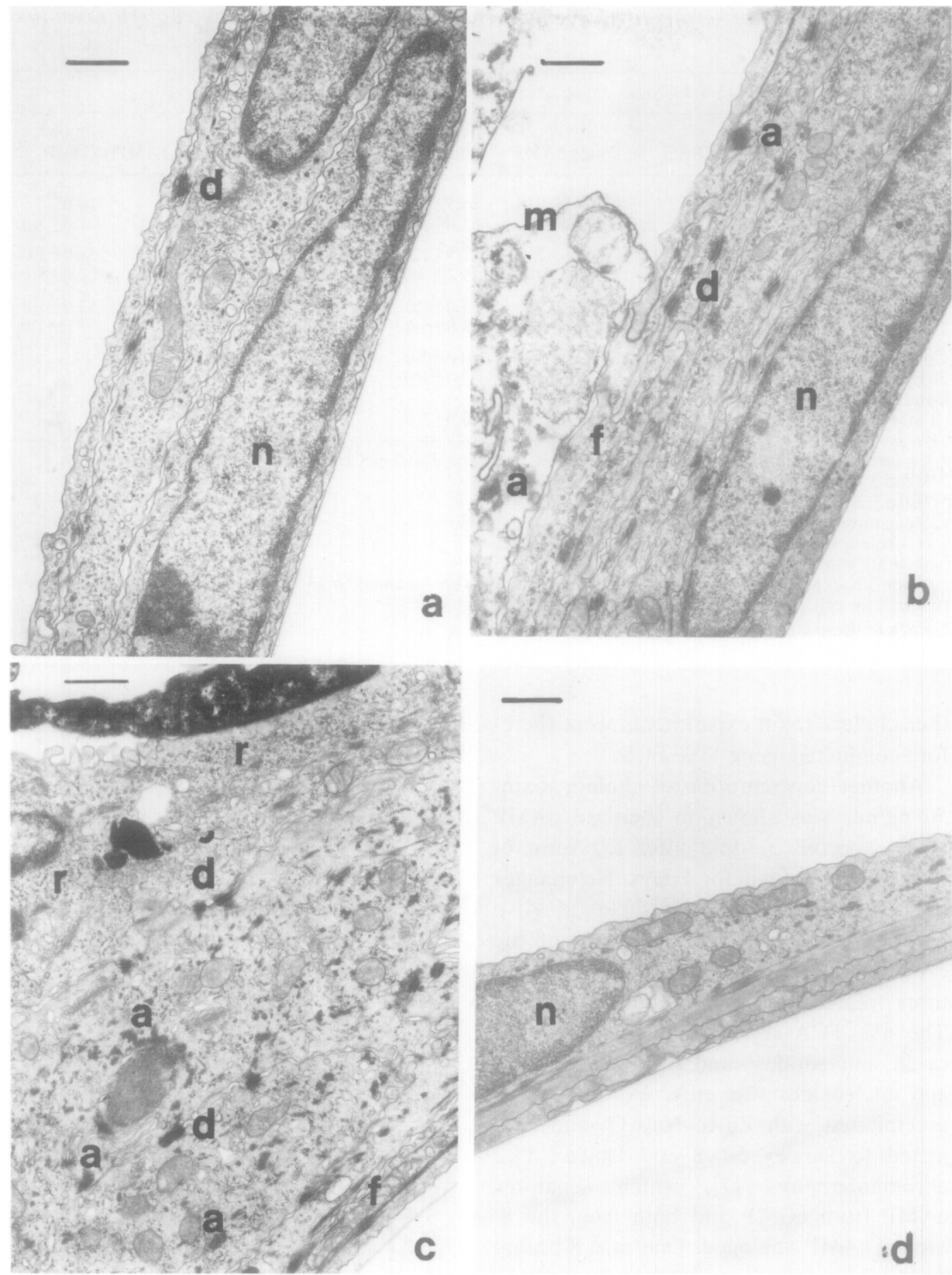


presence of $50 \mu \mathrm{M}$ MIX is presented in fig. 2. $1.0 \mu \mathrm{g} / \mathrm{ml}$ cholera toxin which stimulated the cAMP level approx. 8-fold, $50 \mathrm{ng} / \mathrm{ml}$ cholera toxin which was shown to increase cAMP at day 4 , plus $0.5 \mathrm{ng} / \mathrm{ml}$ and $50 \mathrm{pg} / \mathrm{ml}$ concentrations were added on day 1 . The results, as shown in fig. 2 , indicate that cholera toxin demonstrates a time dependent effect although a longer time course was necessary for stimulation of keratinocyte proliferation by the day 5 time point, which is 4 days of culture in the toxin. The results indicate that 8-fold, 3-fold and possibly lower increases in cellular cAMP (with the $0.5 \mathrm{ng} / \mathrm{ml}$ and $50 \mathrm{pg} / \mathrm{ml}$ doses) can cause from 3- to 10-fold increases in keratinocyte proliferation (fig. 2). No obvious dose response was observed.

The $1 \mu \mathrm{g} / \mathrm{ml}$ concentration of cholera toxin also increased the labeling index from $14 \%$ to $35 \%(p=0.005)$ at day 5 .

\section{Effect of cGMP on keratinocyte proliferation}

The 8-bromo cAMP analogue and cholera toxin in the presence of MIX stimulate keratinocyte proliferation and increase the

Fig. 3. Electron micrographs of $(a)$ control kcratinocyte cultures; $(b)$ keratinocytes treated with $1 \times 10^{-3} \mathrm{M}$ 8-bromo cAMP; (c) cultures treated with $1 \times 10^{-7} \mathrm{M}$ 8 -bromo cGMP; and $(d)$ of cells exposed to $1 \times 10^{-7} \mathrm{M}$ 8-bromo 5'AMP. The drugs were added on day 1 and the cultures were fixed on day 5 . The control culture $(a)$ has 3 cell layers with well formed nuclei $[n]$, and desmosomal complexes $[d]$. The 8-bromo cAMP treated cultures $(b)$ consist of 8 cell layers, including the terminally differentiated upper cell which possesses a thickened cell membrane $[m]$ and aggregated fibrils [a]. The 8-bromo cAMP cultures $(b)$ demonstrate desmosomal complexes $[d]$ and cross- and length-wise fibrils $[f]$. The 8-bromo cGMP treated cultures $(c)$ consist of 5 cell layers. The bottommost cell (against the plastic) has dark and well defined fibrils [f] which do not appear in the controls at any time point. The cell layers are much thicker, possess desmosomal complexes $[d]$ that appear much denser than in the control keratinocytes, large numbers of aggregated fibrils $[a]$ and an abundance of free ribosomes $[r]$. The 8-bromo 5 GMP at a $10^{-7} \mathrm{M}$ concentration had no effect on the cultures. Bar, $0.2 \mu \mathrm{m} . \times 47000$.
cAMP levels of the cultures without any apparent increase in the cGMP levels (table 2). It was possible, however, to postulate a very brief increase in keratinocyte cGMP or an intracellular shift in cGMP levels [31] to account for the observed stimulation since increased levels of cellular cAMP could be effecting cGMP concentrations (temporarily) or localization. To investigate this possibility, $10^{-6}, 10^{-7}$ and $10^{-8}$ 8-bromo cGMP was added to the cultures on day 1 and the rate of ${ }^{3} \mathrm{H}$ uptake into DNA was quantitated on day 4,6 and 8 . As shown in table 3,8-bromo cGMP at these concentrations had no effect on $\left[{ }^{3} \mathrm{H}\right] \mathrm{TdR}$ uptake into DNA. A time and dose response for the 8-bromo cAMP analogue from another experimental set is also presented to contrast the different effects of the two cyclic nucleotides.

\section{Electron microscopy and \\ histochemistry}

Simultaneous with the stimulation of keratinocyte proliferation, 8-bromo cAMP augments the specialization of the cultures as demonstrated by the greatly increased appearance of Kreyberg stainable (red) upper cells layers after 9-14 days of growth in the 8-bromo analogue.

Fig. 3 presents electron micrographs of control $(a)$, a 8-bromo cAMP-treated cultures $(b ; 1 \mathrm{mM})$ as well as $10^{-7} \mathrm{M} 8$-bromo cGMP-treated (c) and $10^{-\tau} \mathrm{M}$ 8-bromo $5^{\prime}$ GMP-treated $(d)$ keratinocytes. The control keratinocyte cultures, as shown in fig. $3 a$, consist of 3 cell layers; desmosomal complexes which are characteristic of the epidermal cells of the skin, conjoin the keratinocytes and there are a few isolated fibrils in the uppermost cells, a characteristic of day 5 cultures [21]. The $1 \mathrm{mM}$ 8-bromo cAMP-treated cultures $(b)$ consist of 8 cell layers, including the uppermost terminally 
differentiated cell which contains a thickened cell membrane $(m)$, electron dense amorphous aggregated fibrils without a limiting membrane $(a)$ and a degenerated nucleus. Desmosomal complexes are evident as is the presence of cross and length-wise fibrils, all characteristic of a more developed culture [21]. The effect of the 8-bromo cAMP analogue is not the result of a temporary 2-3 day 'speeding up' of the culture proliferation-specialization pattern time course since the analogue has been observed to augment proliferation and specialization from day 3-4 to 15 of culture.

Fig. $3 c$ presents cultures treated with $10^{-7}$ M 8-bromo cGMP (day 5). The cultures consist of 5 cell layers which are much 'thicker' than the control or 8-bromo cAMP treated cultures. Thick fibrils $(f)$ run along the bottom-most cell (against the plastic), the desmosomal complexes $(d)$ appear very dense, and large amounts of aggregates $(a)$ and fibrils $(f)$ are seen. In addition, large numbers of free ribosomes are present. This observation, when coupled with the increased size of the cells, suggest that the 8bromo cGMP augmented keratinocyte protein synthesis in a manner possibly unique to cGMP, since none of our observations of control cultures from day 1 to day 30-35 [21] have disclosed keratinocyte layers with this specialization and stratification pattern. 8-Bromo $5^{\prime} \mathrm{GMP}$ at a $10^{-7} \mathrm{M}$ concentration had no effect on the EM morphology of the cultures (fig. $3 d$ ).

\section{DISCUSSION}

The role of cAMP as a positive effector of cell proliferation has been the subject of many reports (see $[1,2]$ for reviews), and cAMP has been recently demonstrated to be a mitogenic signal for cultured rat Schwann cells [32] and a possible DNA syn- thesis initiator signal for BALB/3T3 cell cultures [33]. The data presented in this report indicates that both high and moderate increases in keratinocyte cAMP levels can stimulate proliferation and specialization, and that cGMP can be a qualitative effector of epidermal cell differentiation, both functional events occurring without involvement of fibroblastic or dermal influences. These results are in agreement with the hypothesis that cAMP and cGMP can be metabolic regulators of epidermal proliferation and specialization [34].

Several published investigations report that CAMP analogues and several drugs that can elevate cAMP, inhibited human epidermal cells $[35,36]$ and epidermal mitosis in an in vitro mouse ear assay [37] during the G2 portion of the cell cycle, indicating that cAMP can be a G2 cell blocker in adult epidermis. In an in vivo model, Aso et al. [38] demonstrated that retinoic acid induced increases in mitotic activity and changes in specialization of adult guinea pig ear skin are associated with increases in both the cAMP and cGMP content of the tissue. Delescluse et al. [39] report that $10^{-2}-$ $10^{-4} \mathrm{M}$ db-cAMP inhibits $\left[{ }^{3} \mathrm{H}\right] \mathrm{TdR}$ uptake into guinea pig epidermal cell cultures 1 day after addition. Concomitant with the inhibition is an induction of differentiation of the cells after 6-8 days as reported by Delescluse et al. [40]. The difference between these studies $[39,40]$ in adult guinea pig ear skin that link cAMP with inhibition of proliferation and enhanced differentiation, and the results reported here, i.e., a stimulation of proliferation and specialization observed with increased cAMP levels, could reflect variations in in vitro models and techniques. Such variations may be species variation, adult versus neonatal cells, dissociation procedures, etc.

The use of this in vitro epidermal cell 
system has allowed direct study of the differential effects of elevated cAMP levels and a cGMP analogue on keratinocytes free from dermal influences. The observation that cGMP can qualitatively change the electron microscopic morphology of the keratinocytes at $10^{-7} \mathrm{M}$ concentration without any apparent stimulatory effect was not expected since an increase in cellular cGMP levels has been postulated to be involved in the proliferative events of the cpidermis $[16,34]$. The data suggests that one type of epidermal cell proliferation-specialization program (at least, in vitro) is associated with elevated cAMP levels while a type of specialization function can be effected by cGMP.

Other agents can effect the proliferationspecialization pattern of primary epidermal cell cultures derived from neonatal mice. Investigations reported by Yuspa et al. [41] which we have verified (data not presented) demonstrate that $10^{-7} \mathrm{M}$ TPA (12-O-tetradecanoyl-phorbol-13-acetate), a tumor promoter, stimulates keratinocyte culture proliferation with an almost complete abolition of specialization and differentiation. This dose of TPA induces a proliferative response not associated with an increase in cAMP or cGMP at 2, 5 and $10 \mathrm{~min}, 1$ and $3 \mathrm{~h}$, and 3 days after exposure of the cells to the drug (Marcelo, unpublished results). Yuspa et al. [42] reported that another epidermal cell modifier, retinyl acetate, modulates neonatal mouse epidermal cell cultures by decreasing the labeling index, and by altering the course of specialization (verified by us, data not presented). There are no changes in CAMP and cGMP levels during the initial $3 \mathrm{~h}$ of exposure to the drug (Marcelo, unpublished data). These studies by other investigators and ourselves demonstrate modulation of keratinocyte proliferation and specialization without any ap- parent change in the intracellular cyclic nucleotide concentrations.

The results presented in this report describe the stimulation of a kcratinocytc proliferation-specialization pattern by increases in cellular cAMP levels and alterations of specialization patterns by a cGMP analogue. Retinyl acetate and TPA have been shown to also alter these functions, without any apparent change in the cAMP or cGMP level. These results could allow the formulation of the hypothesis that the epidermal cell, at least in vitro, can undergo cell cycle-functional events associated with alterations in the cyclic nucleotide levels; and can undergo other events seemingly independent of changes in these modulations. However, recent investigations by Koide et al. [31] have demonstrated that alterations in intracellular distribution of cGMP and guanylate cyclase can be found in liver cells undergoing regeneration, suggesting that no change in measurable cAMP or cGMP cell content does not rule out a role for cyclic nucleotides in any one kind of proliferation-specialization event. Therefore, while association of changes in cAMP or cGMP with specific proliferation programs in the skin is an attractive hypothesis, assessment of the validity of this premise must await further investigations which are presently underway.

A preliminary report of this work was presented at the Plenary session of the meeting of the Society of Investigative Dermatology ( $J$ invest dermatol 70 (1978) 221 .

This research was supported by the NIH grant 2 P01 AM-15740.

We wish to thank Dr Yong Gill Kim for providing the electron micrographs.

\section{REFERENCES}

1. Pastan, I H, Johnson, G S \& Anderson, W B, Annual review of biochemistry vol. 44 , p. 491. Annual reviews Inc, Palo Alto (1975). 
2. Friedman, D L, Johnson, R A \& Zeilig, C E, Advances in cyclic nucleotide res (ed P Greengard \& G A Robison) vol. 7, p. 69. Raven Press, New York (1976).

3. Armato, U, Draghi, E \& Andreis, P G, Exp cell res 105 (1977) 337.

4. Holmgren, J, Lange, S, Lindholm, L, Lönnroth, C \& Lönnroth, I, Exp cell res 108 (1977) 31.

5. O'Neill, J P, Schroder, C H, Riddle, J C \& Hsie, A W, Exp cell res 97 (1976) 213

6. Zeilig, C E, Johnson, R A, Sutherland, E W \& Friedman, D L, J cell biol 71 (1976) 515.

7. Chang, J H T \& Prasad, K N, J pediat surg 11 (1976) 847.

8. Kimball, R F, Perdue, S W \& Hsie, A W, Exp cell res 95 (1975) 416.

9. Pawelek, J M, J invest dermatol 66 (1976) 201.

10. Tisdale, M J \& Phillips, B J, Exp cell res 104 (1977) 135.

11. Whitfield, J F, MacManus, J P, Rixon, R H, Boynton, A L, Youdale, T \& Swierenga, S, In vitro 12 (1976) 1.

12. Carr, R H, Busse, W W \& Reed, C E, J allergy and clin immunol 51 (1973) 255.

13. Chambers, D A, Marcelo, C L \& Voorhees, J J, Clinical aspects of cyclic nucleotides (ed L Volicer) p. 407. Spectrum Publications, New York (1977).

14. Mier, P D \& Urselmann, E, Brit j dermatol 83 (1970) 364

15. Voorhees, J J \& Duell, E A, Control mechanisms in cancer (ed W E Criss, T Ono \& J R Sabine) p. 161. Raven Press, New York (1976).

16. Voorhees, J J \& Duell, E A, Advances in cyclic nucleotides (ed G I Drummond, P Greengard \& G A Robison) vol. 5, p. 735. Raven Press, New York (1975).

17. Marcelo, C L, Duell, E A, Stawiski, M A, Anderson, $T$ G \& Voorhees, J J, J invest dermatol. In press

18. Halprin, K M, Adachi, K, Yoshikawa, K, Levine, $\mathrm{V}$, Mui, M M \& Hsia, S L, J invest dermatol 65 (1975) 170 .

19. Iizuka, H, Adachi, K, Halprin, K M \& Levine, V, $\mathrm{J}$ invest dermatol 70 (1978) 246.

20. - Ibid 70 (1978) 250.

21. Marcelo, C L, Kim, Y G, Kaine, J \& Voorhees, J J, J cell biol 79 (1978) 356.

22. Burton, K, Methods in enzymology (ed L Gross- man \& K Moldave) vol. 12, p. 163. Academic Press, New York (1968).

23. Harper, J F \& Brooker, G, J cyclic nucleotide res 1 (1975) 207.

24. Steiner, A L, Kipnis, K M, Utiger, R \& Parker, C, Proc natl acad sci US 64 (1969) 367.

25. Duell, E, Bazner, W \& Voorhees, J J, Fed proc 34 (1975) 333.

26. Iizuka, H, Adachi, $K$, Halprin, $K$ \& I evine, V, J invest dermatol 70 (1978) 250.

27. Adachi, K, lizuka, H, Halprin, K M \& Levine, V, Biochim biophys acta 597 (1977) 428.

28. Moss, J \& Vaughn, M, Proc natl acad sci US $/ 4$ (1977) 4396.

29. Guerrant, R L, Brunton, L L, Schnaitman, T C, Rebhun, L I \& Gilman, A G, Infect and immunol 10 (1974) 320

30. Schultz, G, Methods in enzymology (ed J G Hardman \& B W O'Malley) vol. 38, part c, p. 115. Academic Press, New York (1974).

31. Koide, Y, Earp, H S, Ong, S \& Steiner, A L, J biol chem 253 (1978) 4439.

32. Raff, M C, Hornby-Smith, $\Lambda$ \& Brockes, J P, Nature 273 (1978) 672.

33. Boynton, A L, Whitfield, J F, Isaacs, R J \& Tremblay, R G, Life sci 22 (1978) 703 .

34. Voorhees, J J, Marcelo, C L \& Duell, E A, J invest dermatol 65 (1975) 179.

35. Harper, R A, Flaxman, B A \& Chopra, D P, J invest dermatol 62 (1974) 384.

36. Flaxman, B A \& Harper, R A, J invest dermatol 65 (1975) 52.

37. Voorhees, J J, Duell, E A \& Kelsey, W H, Arch dermatol 105 (1972) 384.

38. Aso, K, Rabinowitz, I \& Farber, E M, J invest dermatol 67 (1976) 231.

39. Delescluse, C, Colburn, N H, Duell, E A \& Voorhees, J J, Differentiation 2 (1974) 343

40. Delescluse, C, Fukuyama, K \& Epstein, W L, J invest dermatol 66 (1976) 8

41. Yuspa, S H, Ben, T, Patterson, E, Michael, D, Elgjo, K \& Hennings, H, Cancer res 36 (1976) 4062.

42. Yuspa, S H, Elgjo, K, Morse, M A \& Wiebel, J, Chem biol interactions 16 (1977).

Received August 15, 1978

Revised version received November 23, 1978

Accepted November 23, 1978 